\title{
PENGEMBANGAN FUNGSI KEYBOARD: SUATU ALTERNATIF UPAYA PELESTARIAN MUSIK GAMELAN
}

\author{
oleh Cipto Budy Handoyo \\ FBS Universitas Negeri Yogyakarta
}

\begin{abstract}
Uneasiness of a nation with pushed for existension in the some things is a real things. Our nation, Indonesia with many cultural of tribe, naturally decent to feel pushed with the other cultural from the other nation

The feel with pushed our nation Indonesia, example about the cultural of tribe like music in Java Island with Javanese "orchestra": Gamelan. Now, Gamelan is really pushed with the curtural from other country. Generally, the people of Indonesia really can not enjoy with the Javanese Music: Gamelan. They do not have sense of belonging with their music: Gamelan. They more like the music from other country. We can see this from the young generation that more like to play or enjoy the music from other country.

Therefore, by develope the function of the instrument of music Keyboard (Organ) is one concrete alternative for make people of Indonesia like the music of Gamelan by listen it. By listen the Gamelan with Keyboard cotinously at many event, we hope we can at least to enjoy our music selve: Gamelan, then we can to learn it.
\end{abstract}

Key words: Keyboard, Gamelan.

\section{A. Pendahuluan}

Arus globalisasi makin lama semakin deras dan semakin tak terbendung. Dunia seolah semakin terasa "kecil", ibarat hanya di dalam "genggaman tangan". Teknologi demikian pesatnya berkembang. Informasi-informasi sejauh manapun hanya sekejap dapat ditemukan hanya di depan monitor komputer melalui Internetnya.

Masih banyak lagi perkembangan kemajuan teknologi yang terus meningkat ke arah yang lebih maju. Di dalam dunia Musik sebagai contoh salah satunya, kemajuan teknologinya juga mengalami perkembangan yang luar biasa. Salah satu kemajuan teknologinya dalam dunia musik salah satunya adalah teknologi dalam pengembangan fungsi alat musik yang dikenal dengan istilah Keyboard (baca: kibot). Alat musik keyboard ini dalam jangka waktu yang tidak terlalu lama (dapat dikatakan

Pengembangan Fungsi Keyboard: Suatu Alternatif Upaya ... (Cipto Budy Handoyo) 
dalam ukuran bulan) sudah mengalami perkembangan teknologi: kecanggihannya yang luar biasa. Dari fungsi umum yang hanya sebagai salah satu alat musik biasa : sebut saja Organ (boleh dibaca : orjen); alat musik yang semula hanya dipergunakan untuk mengiringi lagu-lagu Rohani di dalam Gereja, sampai terakhir kini keyboard mampu melayani berbagai keinginan Kreatif manusia. Keyboard kini dapat pula menirukan berbagai macam suara tidak hanya suara alat musik seperti: suling, gitar, terompet, biola, drum (baca: dram), juga bunyi alat musik gamelan, dan sebagainya. Keyboard kini mampu menirukan bunyi apa saja yang ada di dunia ini.

Di lain pihak derasnya arus globalisasi ini mampu membuat kecemasan bangsa Indonesia dalam banyak hal, antara lain bangsa cemas terhadap punahnya budaya dan nilai-nilai luhur bangsa (Indonesia tentu saja). Tentu saja demikian, karena dengan berbagai kemudahannya banyak budaya bangsa Asing masuk tanpa dapat dibendung dengan berbagai cara.

Suatu kenyataan yang terasa benar adalah bahwa generasi mudanya terlihat begitu menikmatinya hidup dengan budaya asingnya. Diakui atau tidak sebagai salah satunya: dalam berpakaian, anak-anak muda (khususnya kaum wanitanya) begitu menyukai mengenakan baju yang mengekspos "Aurot"nya (bagian perut dan pantatnya, juga "CD"nya benar-benar kelihatan). Inilah yang dimaksudkan dengan pengaruh budaya asing, khususnya dalam hal berbusana.

Dalam kekayaan budaya bangsa Indonesia, khususnya yang berkait dengan kesenian yang benar-benar asli dari Indonesia sebut saja salah satunya: Gamelan, bukan tidak mungkin ia (gamelan) akan tergusur dan menjadi barang tua yang tidak akan disentuh lagi bagi pemilik aslinya: bangsa Indonesia. Ini dimungkinkan terjadi karena kekuatan desakan budaya asinglah melalui arus globalisasi tersebut, atau dengan kata lain oleh karena kelemahan diri kita sendiri sebagai bangsa Indonesia dalam melestarikannya.

Memperhatikan fenomena di atas, perlu kiranya setidak-tidaknya dikembangkannya pemikiran, gagasan, untuk mengupayakan langkah nyata menyelamatkan kekayaan tradisi bangsa, termasuk menyelamatkan gamelan sebagai musik asli Indonesia khususnya di Jawa.

\section{B. Keyboard atau Organ?}

Di depan telah disinggung tentang sebuah alat musik dengan kecanggihannya yang mampu menirukan bunyi apa saja sesuai yang dikehendaki orang yang memprogramnya, yang kita kenal sebagai keyboard. Alat musik ini memang tidak lagi menjadi alat musik yang asing bagi kita semua. Alat musik yang cara membunyikannya dengan cara menekan tuts-tutsnya yang berjajar pada alat musik tersebut inilah yang disebut sebagai alat musik Keyboard (Ulrich, 1970: 23).

Imaji.Vol.3. No.2. Agustus 2005 : 257 - 272 
Keyboard kini mudah sekali untuk mendapatkannya, bahkan dengan harga yang benar-benar murah. Kita dapat menjumpainya keyboard dijual di jalan-jalan dengan harga yang "fantastis" murahnya. Namun, jangan salah, keyboard yang ini hanya mampu memproduksi bunyi terlalu amat sederhana sekali. Tentu saja tidak tergolong keyboard yang dipaparkan di depan. Namun demikian, paling tidak dalam hal sekedar mengenal wujud alat musik keyboard, keyboard yang dijual di jalanjalan cukup memberikan pengetahuan: bahwa itulah salah satu contoh alat musik yang termasuk Keyboard.

Berdasarkan paparan di atas, kita dapat mengetahui alat-alat musik yang tergolong keyboard. Di tengah-tengah masyarakat telah dijumpai berbagai alat musik yang menggunakan tuts-tutsnya sebagai alat yang membunyikannya. Alat-alat musik ini antara lain: Pianika (Melodion), Piano, Akordeon, Organ, dan sebagainya. Jadi, organ adalah salah satu alat musik yang tergolong keyboard (Ulrich, 1970: 70).

Kini istilah keyboard dan organ tidak perlu lagi diperdebatkan yang mana yang tepat menyebutnya. Yang jelas, pengertian keyboard di tengah masyarakat telah diketahui tidak lain adalah organ. Jadi keyboard sebenarnya sebuah istilah yang menunjuk kelompok alat musik yang menggunakan tuts-tuts sebagai alat pembunyinya.

\section{Gamelan: Musik Jawa?}

Gamelan adalah salah sebuah pernyataan musical berupa kumpulan alatalat musik (bunyi-bunyian) tradisional dalam jumlah besar yang terdapat (terutama) di Pulau Jawa (Yudoyono, 1984: 15).

Cukup dapat difahami apabila suatu bangsa mencemaskan kekayaan budayanya terancam tertindas oleh budaya bangsa asing. Gamelan adalah salah satu kekayaan musik yang dimiliki bangsa kita Indonesia.

Gamelan di Indonesia lebih dikenal di Jawa: Jawa Tengah, DIY, Jawa Barat, Jaw a Timur (Yudoyono, 1984: 15). Di daerah-daerah lain di Indonesia memang ada seperti di Bali ada Gamelan Bali dengan karakteristik dan keunikan tersendiri, dan lain-lainnya.

Baik gamelan Jawa maupun gamelan Bali dan juga gamelan-gamelan lain yang terdapat di Indonesia, semua itu adalah alat musik yang benar-benar milik kita sendiri. Persoalannya, mengapa bangsa kita sendiri semakin terkesan menjauh, tidak mau menyentuhnya, seperti begitu akrabnya menyentuh alat-alat musik bangsa lain.

Fenomena yang menarik berkait dengan fenomena tersebut di atas beragam. Ada suatu contoh di masyarakat, ada seorang yang benar-benar menghayati dan 
bagus ketika menyanyikan lagu-lagu Jawa yang beringan gamelan. Tidak lama kemudian teman-temannya mengolok-oloknya, mengejeknya setelah menyanyikan lagu tersebut. Efek yang nampak setelah kejadian itu, anak tersebut begitu malu, dan terkesan langsung ingin meninggalkan kemampuan yang alami tersebut. Kejadian ini benar-benar memprihatinkan, walau mungkin bersifat kasus saja. Tapi setelah diamati benar fenomena yang ada dalam masyarakat, begitu jarangnya generasi muda memainkan alat musik gamelan ini ataupun bergabung dengan menyanyikan lagu-lagu yang diiringi gamelan.

\section{Sekilas Karakteristik Alat Musik Gamelan}

Telah dipaparkan di depan bahwa ternyata Gamelan di Indonesia tersebar tidak hanya di Jawa saja, melainkan di berbagai daerah lainnya seperti Bali dan lain-lain. Oleh karena kita ketahui bersama bahwa di Indonesia, daerah-daerah memiiiki karakteristik, kekhasan sendiri-sendiri walaupun sama-sama sebut saja gamelan.

Baik gamelan Jawa maupun Bali dan daerah lainnya yang memiliki alat musik daerah yang serupa dengan gamelan, pada umumnya alat musik ini lebih banyak perkusinya. Gamelan Jawa Tengah dan juga Jawa Timur sebagai contoh, alat-alat musiknya antara lain: Saron, Bonang, Kenong, Kempul, Gender, Kendang, dan sebagainya. Alat-alat tersebut semua dibunyikan dengan cara dipukul (perkusi). Gamelan Jawa Tengah termasuk Yogyakarta (DIY) juga Jawa Timur, mengenal dua jenis, yaitu Pelog dan Slendro.

\section{Gamelan Pelog}

Secara lengkap gamelan pelog memiliki 7 nada (Yudoyono, 1984: 17). Tetapi dilihat dari keseringan penggunaannya, gamelan Pelog ini memiliki nada pokok ada 5 (lima), makanya sering disebut pentatonic (penta: lima, tonic/tone: nada). Kelima nada pokok tersebut adalah: 1 (ji), 2 (ro), 3 (lu), 5 (mo), 6 (nem). Sedangkan nada lainnya adalah: 4 (pat) dan 7 (pi). Kedua nada ini digunakan pada keperluankeperluan tertentu sesuai dengan pathet (mirip dengan istilah musik umum: Nada Dasar).

Untuk membantu membayangkan bagaimana karakteristik nada-nada Pelog ini, "orang musik umum" sering menggunakan istilah: Kuasi (penyamaan dengan nada-nada musik umum: Diatonic). Jadi, "orang musik umum" menganggap sama (apabila deretan nada-nada gamelan Pelog: 1 (ji), 2 (ro), 3 (lu), 5 (mo), 6 (nem)

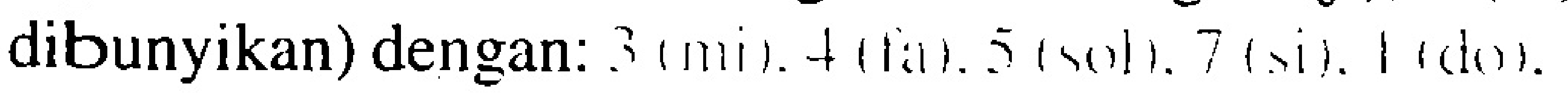

Imaji.Vol.3. No.2. Agustus 2005 : 257 - 272 
Uniknya, Kuasi tersebut di atas dapat berubah kalau Pathetnya beda, walaupun sama-sama nada/laras 6 (nem) misalnya. Sementara itu, apabila dicek konsistensi frekuensinya tentu saja terkesan mengalami pemaksaan. Sebagai contoh, pada Pathet Barang, nada/laras 6 (nem) ini tidak lagi terkuasi menjadi 1 (do) lagi, melainkan: 4 (fa). Di sinilah uniknya lagi pada gamelan ini, pada pathet, barang ini tidak menggunakan nada/laras 1 (ji) di samping tidak juga menggunakan laras 4 (pat).. Pada pathet ini nada/laras lainnya terkuasi menjadi: 2 (ro) $=7$ (si), 3 (lu) $=$ $1(\mathrm{do}), 5(\mathrm{mo})=3(\mathrm{mi}), 6(\mathrm{nem})=4(\mathrm{fa}), 7(\mathrm{pi})=5(\mathrm{sol})$.

Perhatikan kembali pada kuasi sebelum contoh pada pathet barang ini. Dikatakan tidak konsisten dalam hal frekuensinya, karena mestinya apabila kuasi pertama 2 (ro) $=4$ ( $\mathrm{fa}$ ) dan $3(\mathrm{lu})=5$ ( $\mathrm{sol}$ ), maka bagi "orang musik umum" memastikan bahwa jarak dari not 4 (fa) ke 5 (sol) adalah 1 (satu), sedangkan pada pathet barang 2 (ro) menjadi 7 (si), 3 (lu) menjadi I (do), padahal jarak not 7 (si) ke 1 (do) adalah $1 / 2$ (setengah). Apabila diukur frekuensinya, jarak $1 / 2$ jelas berbeda dengan jarak 1 . Uniknya, begitu menyanyi dengan lagu yang sama dengan pathet yang berbeda, perubahan fungsi nada terkuasi tersebut tidak benar-benar terasa bila mendengarkannya.

\section{Gamelan Slendro}

Dilihat dari jumlah nadanya, Gamelan Slendro ini hanya memiliki nada 5 (lima). Jadi tidak memiliki nada lainnya lagi seperti pada gamelan pelog. Kelima nada-nada tersebut adalah: 1 (ji), 2 (ro), 3 (lu), 5 (mo), 6 (nem) (Yudoyono, 1984: 17).

Pada gamelan slendro ini, untuk membantu membayangkan bagaimana karakteristik nada-nadanya juga menggunakan Kuasi. Jadi, "orang musik umum" menganggap sama (apabila deretan nada-nada gamelan Slendro: 1 (ji), 2 (ro), 3 (lu), 5 (mo), 6 (nem) dibunyikan) dengan bunyi nada: 3 (mi). 5 ( $(\mathrm{sol}) .6$ (la), 1 (do), 2 (re). Pada gamelan slendro juga ada pathet-pathet, di mana memiliki keunikan yang sama, untuk kuasinya, yaitu ketidakajegan selisih frekuensi antar nadanya. Selisih frekuensi antar nada ini digambarkan pada system nada musik umum (di Indonesia khususnya) dengan sebutan: jarak atau ada yang menyebutnya: interval.

\section{E. Keyboard Canggih versus Gamelan}

Di tengah kecemasan bangsa Indonesia berhadapan dengan derasnya arus globalisasi yang cukup mengancam kepunahan budaya bangsa termasuk punahnya musik gamelan sebagai salah satu kekayaan budaya di Indonesia, keyboard justru merupakan sebuah penawaran untuk dikembangkan sebagai alat untuk merekayasa 
upaya melestarikan musik gamelan. Paling tidak melalui mendengarkan hasil rekayasa peniruan bunyinya, orang yang mendengarnya jadi seperti mendengarkan bunyi gamelan. Justru dengan kecanggihan keyboard pada tahun-tahun terakhir ini, keyboard difasilitasi dengan fasilitas yang menawarkan bagi orang yang mau secara kreatif mengembangkan fungsi keyboard tersebut, termasuk memprogram agar dapat menirukan bunyi gamelan dengan komposisi lagu-lagunya.

Berkaitan dengan kecemasan punahnya gamelan di Indonesia tersebut seperti terungkap di atas, kini dengan kecanggihannya ternyata keyboard mampu melayani kita yang kreatif. Keyboard dengan merek dan spesifikasi tertentu siap diprogram agar dapat memproduksi dan memainkan orkestrasi gamelan. Yang dimaksudkan dengan orkestrasi gamelan kurang lebih adalah pengaturan bunyibunyi alat musik gamelan yang banyak menjadi satu sajian musik yang dimainkan bersama-sama.

Keyboard yang memiliki kemampuan secara canggih seperti dipaparkan di atas, kini sudah banyak dengan berbagai merek dan spesifikasi, sehingga dapat memprogramnya sesuai dengan kesenangan yang memprogram. Merek-merek keyboard ini antara lain: Korg, Rolland, Technics, Yamaha, Casio. Yang jelas keyboard dengan kecanggihan masing-masing, juga memiliki kelebihan dan kekurangan sendiri-sendiri. Masing-masing keyboard telah berlomba-lomba memfasilitasi diri dengan bunyi-bunyi alat-alat musik etnik termasuk gamelan, tinggal bagaimana mengembangkannya sesuai dengan kepentingannya.

\section{F. Mengembangkan Fungsi Keyboard}

Seperti telah disinggung di depan, keyboard cangih telah dilengkapi bunyibunyi alat musik etnik termasuk gamelan, seperti: saron, bonang, kenong, gender, kempul, gong, kendang, dan sebagainya. Untuk itu, untuk keperluan memainkan alat musik gamelan, tinggal kita dapat mengorkestrasi atau mengaransirnya sesuai dengan kreativitas kita. Di samping itu, keyboard canggih juga dilengkapi dengan fasilitas untuk mencipta bunyi alat musik gamelan lainnya apabila dikehendaki.

Oleh karena keyboard kini telah banyak yang canggih, maka untuk mengembangkan fungsinya tidak terlalu sulit. Berikut ini contoh langkah mengembangkan fungsi keyboard untuk dimainkan sebagai "orkes" gamelan.

\section{Sebelum Pemprograman}

a. Pilih salah satu lagu yang dinyanyikan dengan iringan gamelan

Lagu yang diiringi musik gamelan biasa disebut Tembang. Apabila lagu tersebut berbahasa Jawa, lagu tersebut antara lain berupa Langgam Jawa. Untuk memilih lagu ini tidak sulit, kita bisa mendapatkannya di toko-toko kaset atau CD, 
ataupun VCD. Ambil saja lagu yang tidak terlalu rumit, sebagai contoh Ngidam Sari (karya: Mantous). Lagu ini sering diiringi gamelan, tetapi sudah dicampur/ dipadu dengan alat musik umum seperti Bass, dan lain-lain, sehingga penyajian yang demikian pada umumnya disebut musik Campursari.

Dalam memilih lagu, di samping sederhana, sedapat mungkin lagu yang banyak dikenal orang. Lagu Ngidam Sari merupakan salah satu lagu yang memang cukup dikenal orang, sehingga dapat dipilih.

Sesuai dengan tujuan utama pada tulisan ini, bahwa ini merupakan langkah alternatif untuk melestarikan musik gamelan. Setelah orang diperdengarkan secara berulang bunyi gamelan melalui alat musik kibot, diharapkan paling tidak orang akan mengingat bahwa kita bangsa Indonesia memiliki kekayaan musik tradisional berupa gamelan. Pada tahap berikutnya paling tidak kita akan tetap menyukai musik gamelan. Tidak dilupakan begitu saja.

\section{b. Pelajari lagu tersebut dengan tuntas}

Dengan mempelajari lagu hingga tuntas terutama: melodi, iringan, bunyi alat-alat musiknya, maka kita akan lebih mudah menirukannya baik dalam bentuk menyanyikannya, maupun menirukannya dalam alat musik keyboard.

\section{Pemprograman}

Untuk memprogram keyboard agar dapat berfungsi menirukan bunyi-bunyi alat musik Gamelan, keyboard memiliki prosedur sendiri-sendiri tergantung merek dan spesifikasi keyboardnya. Untuk memprogram peniruan bunyi alat-alat musik gamelan, keyboard kini telah banyak dan berlomba menarik simpati pemakai/ konsumen sesuai dengan daerah pemasarannya. Merek-merek yang berlombalomba menarik perhatian orang Indonesia khususnya untuk menirukan bunyi alatalat musik gamelan antara lain: Korg, Yamaha, dan Technics. Masing-masing memiliki kelebihan dan kekurangannya sendiri-sendiri, sehingga apabila kita ingin memilikinya, perlu meneliti kemampuan, kelebihan, dan kekurangan masing-masing sesuai dengan kepentingannya. Persoalannya adalah, ketika kita sudah terlanjur terobsesi merekayasa keyboard agar dapat secara mirip menirukan bunyi gamelan, maka Kendang merupakan alat musik yang musti dipikirkan bagaimana membuat/ memprogramnya, sebab bunyi-bunyi alat-alat muik gamelan mungkin banyak keyboard dapat menirukannya, tetapi pada umumnya mereka tidak dilengkapi (dari pabriknya) bunyi kendang lengkap: tak, tung, dah, dhung, dan sebagainya.

\section{a. Memprogram Bunyi Kendang}

Seperti telah disinggung di depan bahwa pada umumnya keyboard yang beredar di Indonesia kini telah dilengkapi dengan bunyi-bunyi tiruan gamelan seperti 
paling tidak: saron, gender, dan lain-lain. Ternyata bunyi kendang secara lengkap tidak disediakan. Tetapi bagi pemakai yang kreatif, tidak jadi masalah, karena keyboard juga dilengkapi dengan fasilitas "Sound Edit" yang dapat mencipta/ mengkreasi bunyi tiruan alat musik apa saja termasuk kendang gamelan. Untuk mencipta bunyi kendang berikut dicontohkan memprogramnya dengan keyboard bermerek Technics dengan spesifikasi: KN2400.

1) Hidupkan keyboard dengan menekan tombol On/Off setelah dihubungkan dengan sumber listrik.

2) Tekan tombol Drum Kit (terletak pada deretan tombol "Sound Group").

3) Pilih User Kit.

4) Tekan tombol "Program Menus".

5) Pilih "Sound Edit" dengan menekan tombol yang letaknya pada posisi "Sound Edit" pada layar kibot.

6) Pilih tuts yang akan diprogram berbunyi Kendang Perlu diketahui Kendang Gamelan Jawa khususnya Jawa Tengah juga Yogyakarta, bunyi-bunyinya antara lain : Tak, Tung, Dhet, Dhung, Dah, Ket.

7) Mari kita mulai dengan membuat bunyi Tak dulu :

8) Letakkan calon bunyi Tak pada salah satu tuts dengan cara menekan anak panah ke atas (ã) atau ke bawah (ä) pada layar keyboard. Misal kita letakkan pada tuts C3. Perhatikan: pada layar keyboard C3 ini sudah ada namanya, agar tidak bingung, tulis lebih dulu nama bunyi Kendang yang akan dibuat, dengan cara:

a) Tekan tombol yang yang lurus dengan posisi "DETAIL EDIT" pada layar keyboard.

b) Tekan tombol yang yang lurus dengan posisi "DRUM SOUND" pada layar keyboard.

c) Beri nama bunyi alat musik gamelan yang akan dibuat (misal: Tak).

d) Tekan tombol yang yang lurus dengan posisi "OK" pada layar keyboard.

e) Tekan tombol EXIT.

1. Pilih Group "R" dengan cara:

a) Tekan panah ke bawah (ä) yang sebelah kiri pada layar keyboard ke arah "Group".

Im aji.Vol.3. No.2. Agustus 2005 : 257 - 272 
b) Tekan tombol panah ke atas(ã) atau ke bawah (ä) untuk menemukan "R".

2. Pilih Group "Conga3 MutSlp" dengan cara:

a) Tekan panah ke bawah (ä) yang sebelah kiri pada layar keyboard ke arah "Tone Name/Dynam".

b) Tekan tombol panah ke atas(ã) atau ke bawah (ä) untuk menemukan "Conga3 MutSlp".

3. Sambil mencek hasil kreasi/ciptaan bunyi Tak yang baru dikerjakan (yaitu dengan menekan tombol C3), dapatkan bunyi yang lebih sesuai dengan kehendak kita dengan merubah angka-angka/nilai-nilai yang terdapat pada layar.

4. Tekan tombol "Write", maka tiruan bunyi yang baru kita kerjakan disimpan sementara pada keyboard (belum ke dalam Floopy Disk).

5. Lakukan langkah yang sama dengan langkah nomor 5 .

6. Lakukan langkah yang sama dengan langkah nomor 6 untuk membuat bunyi “Tung". Misal kita letakkan bunyi "Tung" ini pada tuts A2.

7. Lakukan cara yang persis sama dengan langkah nomor 7.

8. Dengan cara yang sama dengan langkah nomor 8, pilih "Congal Open".

9. Lakukan dengan cara yang sama dengan langkah 9 untuk mendapatkan bunyi sesuai dengan yang kita kehendaki.

10. Lakukan langkah yang sama dengan langkah nomor 6 untuk membuat bunyi "Dhet". Misal kita letakkan bunyi "Dhet" ini pada tuts F2.

12. Lakukan cara yang persis sama dengan langkah nomor 7 .

13. Dengan cara yang sama dengan langkah nomor 8, pilih "Conga3 Mute".

14. Lakukan dengan cara yang sama dengan langkah 9 untuk mendapatkan bunyi sesuai dengan yang kita kehendaki.

15. Lakukan cara yang sama dengan langkah nomor 5.

16. Lakukan langkah yang sama dengan langkah nomor 6 untuk membuat bunyi "Dhung". Misal kita letakkan bunyi "Dhung" ini pada tuts E2.

17. Lakukan cara yang persis sama dengan langkah nomor 7.

18. Dengan cara yang sama dengan langkah nomor 8 , pilih "Conga3 ptn-b8".

19. Lakukan dengan cara yang sama dengan langkah 9 untuk mendapatkan bunyi sesuai dengan yang kita kehendaki.

Pengembangan Fungsi Keyboard: Suatu Alternatif Upaya ... (Cipto Budy Handoyo) 
20. Lakukan cara yang sama dengan langkah nomor 5 .

21. Lakukan langkah yang sama dengan langkah nomor 6 untuk membuat bunyi "Dah". Misal kita letakkan bunyi "Dah" ini pada tuts C2.

22. Lakukan cara yang sama dengan langkah nomor 7 , tapi pilih "P".

23. Dengan cara yang sama dengan langkah nomor 8 (pada posisi "P"), pilih "Dance Tom".

24. Lakukan dengan cara yang sama dengan langkah 9 untuk mendapatkan bunyi sesuai dengan yang kita kehendaki.

25. Lakukan cara yang sama dengan langkah nomor 5 .

26. Lakukan langkah yang sama dengan langkah nomor 6 untuk membuat bunyi "Ket". Misal kita letakkan bunyi "Ket" ini pada tuts G2.

27. Lakukan cara yang persis sama dengan langkah nomor 7 .

28. Dengan cara yang sama dengan langkah nomor 8, pilih "Conga Mute".

29. Lakukan dengan cara yang sama dengan langkah 9 untuk mendapatkan bunyi sesuai dengan yang kita kehendaki.

\section{b. Memprogram Orkes Gamelan}

Istilah "Orkes" pada gamelan di sini adalah dalam rangka menunjuk pada sebuah perpaduan alat musik gamelan yang demikian banyak. Gamelan yang lengkap mempunyai kira-kira 75 alat (Yudoyono, 1984: 15). Ada istilah yang lebih tepat untuk mengatakan perpaduan alat musik gamelan yang banyak ini, yaitu Ansambel. Namun, di sisi lain, pernah di tulis dalam massmedia, bahwa gamelan dapat disebut sebagai "orkes". Mengapa tidak, di Indonesia istilah "orkes" secara umum bukan istilah yang asing, karena dari dulu Musik Dangdut juga masyarakat mengenalnya sebagai Orkes Dangdut. Padahal alat musiknya hanya kurang lebih 7 macam saja.

Untuk memprogram orkes gamelan dalam keyboard ada dua cara, yaitu: song dan style. Song di dalam keyboard dikenal sebagai bunyi perpaduan beberapa alat musik yang terdapat dalam keyboard (misal: bass, gitar, piano, drums, dan sebagainya), yang merupakan hasil pemrograman secara utuh berupa satu lagu penuh. Untuk membunyikan song ini, kita hanya menekan tombol start, maka musik jalan dengan sendiri seperti layaknya sebuah kaset dengan sebuah lagunya. Dengan song ini, pemain keyboard tidak perlu memainkan lagi keyboardnya, karena sudah secara utuh suatu lagu yang diprogram bunyi sendiri, tinggal menambahi vokalnya dengan microphone.

Im aji.Vol.3. No.2. Agustus $2005: 257-272$ 
Style pada keyboard dikenal sebagai Iringan. Untuk mengiringi sebuah lagu yang dinyanyikan seorang penyanyi, pemain keyboard musti menguasai macammacam akord (chord: paduan beberapa nada yang jika dibunyikan bersama-sama menghasilkan bunyi yang harmonis/selaras). Pemain keyboard harus tahu pasti akord yang tepat untuk melodi-melodi yang terdapat pada lagu yang dinyanyikan seorang penyanyi, dan memainkannya.

Setelah di depan kita berhasil memprogram tiruan bunyi gamelan (khususnya kendang, sebab tiruan bunyi yang lain untuk keyboard canggih yang beredar di Indonesia sudah banyak disediakan dari pabriknya), maka selanjutnya kita dapat memprogram paduan bunyi gamelan, sebut saja "orkes gamelan" dengan song atau style. Baik dengan song maupun style, asal alat musik gamelan yang cukup menonjol di dalam permainan musik gamelan yaitu Kendang sudah terprogram, maka pembuatannya/pemprogramannya tidak lagi mengalami kesulitan.

Untuk sebuah contoh lagu yang dipilih di depan yaitu misal lagu yang cukup populer yaitu: Ngidam Sari karya Mantous, secara sederhana dapat dilakukan lebih cepat dengan Style. Kelemahannya, pada style maksimal kita hanya dapat menyusun/memadu bunyi gamelan sebanyak 7 macam. Apabila yang akan kita buat paduan musik gamelan, paling kita hanya dapat menyusunnya alat-alat gamelan: saron, saron kecil (peking), gender, bonang, kenong, gong, dan kendang. Tetapi, jika dalam memprogramnya cukup kreatif, bunyi yang hanya terdiri dari 7 macam alat gamelan tersebut dapat menghasilkan paduan yang menarik. Berikut dicontohkan pemgropraman dengan style:

1. Tekan tombol "Program Menus".

2. Tekan "Composer" (lihat pada layar).

3. Pilih salah satu di antara A, B, atau C. Jika kita memilih A, maka artinya kita akan membuat Style di dalam Grup A. Perlu diketahui bahwa keyboard Technics termasuk seri KN2400 memiliki kemampuan membuat style sebanyak 3 grup (A, B, dan C). Masing-masing grup memiliki 4 variasi. Kita bisa memilih membuat style dari manapun. Misal kita pilih A.

4. Tekan "MEM CLR" (pada layar keyboard).

5. Tekan "YES" (pada layar keyboard).

6. Tulis nama style yang akan dibuat.

7. Tekan "OK" (pada layar keyboard). Begitu kita menekan "OK", maka artinya kita akan mengisi "VAR1" (variasi 1). Kita dapat mengisi VAR2, VAR3, VAR4, dan yang lainnya dengan cara menekan tombolnya sesuai dengan yang tampak pada layar.

8. Tekan "OK" (pada layar keyboard).

Pengembangan Fungsi Keyboard: Suatu Alternatif Upaya ... (Cipto Budy Handoyo) 
9. Mulailah memprogram.

Dalam memulai memprogram, boleh dari mana saja terserah kita. Misal kita mulai dari "BASS", maka silakan langsung tekan "BASS" (lihat layar) hingga pada tulisan "BASS" muncul tulisan "REC". Begitu ditekan, maka akan ad bunyi : tek, tek, tek, tek, ..... Itu adalah bunyi Metronome (pengatur tempo/kecepatan, dan ketukan). Kecepatan ini dapat diatur sesuai dengan kehendak kita dengan menekan ke atas atau ke bawah. Ke atas artinya tempo dipercepat, ke bawah artinya tempo diperlambat. Tombol tempo ini terdapat pada deretan tombol sebelah kiri bawah layar keyboard.

10. Mainkan Bass sesuai dengan kreasi kita.

Untuk mengisi program bagian Bass ini dapat dilakukan dengan 2 cara:

a. Langsung tekan nada-nada Bass yang kita inginkan dengan cara menekan tombol "SYNCHRO \& BREAK" lebih dulu. Begitu tombol ini ditekan akan menyala merah. Tombol ini letaknya di deretan tombol keyboard sebelah bawahnya layar keyboard.

b. Tekan tombol "START" dulu baru membunyikan/memainkan nadanada Bass sesuai dengan kreasi kita.

11. Mainkan alat musik lainnya dengan menekan: "AC1", "AC2", "AC3", "AC4", dan "AC5" (pada layar keyboard). Anggap yang baru saja kita isikan pada Bass adalah Kempul (alat musik gamelan yang berfungsi seperti Bass pada musik umum), maka bagian $\mathrm{AC}$ ini silakan diisi dengan bunyibunyi gamelan lainnya sesuai dengan kreasi kita. Kita dapat memilih bunyibunyi gamelan dengan cara:

a. Tekan tombol "MALLET \& ORCH PERC". Tombol ini terletak pada deretan tombol "SOUND GROUP" (terletak di sebelah kanan layar keyboard).

b. Pilih alat musik gamelan di antara: Kenong, Bonang, Saron. Layar kibot yang menampung alat-alat musik ini terdiri dari 3 halaman (page $1 / 3$, page $2 / 3$, dan page $3 / 3$ ). Page $1 / 3$ artinya halaman 1 dari 3 halaman. Untuk kenong, bonang, dan saron bisa kita dapatkan pada halaman 3 dengan menekan tombol "PAGE" yang terletak pada pojok kanan bawah layar keyboard.

12. Tekan tombol "EXIT".

13. Mainkan alat musik yang telah dipilih.

14. Lakukan dengan cara yang sama dengan langkah nomor 9 sampai 13 untuk mengisi "AC2", "AC3", "AC4", dan lainnya dengan bunyi-bunyi gamelan.

Imaji.Vol.3. No.2. Agustus 2005 : $257-272$ 
15. Sekarang mainkan Kendang yang telah kita buat. Kendang ini tersimpan dalam "USER KIT" yang terletak dalam tombol "DRUM KITS" pada halaman 3 (terdapat pada deretan tombol "SOUND GROUP").

16. Tekan tombol "EXIT".

17. Tekan tombol "DR1" atau "DR2" (pada layar keyboard).

18. Mainkan Kendangnya.

Ingat, letak bunyi-bunyi kendang yang telah kita program (tak, tung, dhet, dhung, dah, ket) terletak pada tuts-tut : C3, A2, F2, E2, C2, G2.

19. Lakukan dengan cara yang sama dengan langkah-langkah nomor 7 sampai dengan 18 dengan lebih dulu menekan tombol "EXIT" sebanyak 2 kali, untuk mengisi VAR2, VAR3, VAR4, dan lainnya.

20. Keyboard siap membunyikan "orkes" gamelan dengan cara memainkannya seperti layaknya mengiringi lagu: tangan kiri memainkan akord, tangan kanan memainkan isian-isian.

\section{c. Menyimpan Hasil Kreasi Tiruan Bunyi ke dalam Disket}

Hasil pemrograman yang sudah dianggap selesai dikerjakan, harus disimpan ke dalam alat penyimpan data. Alat penyimpan data untuk kibot pada umumnya berupa Disket., khususnya kibot Technics seri KN2400. Namun belakangan kibot ada yang alat penyimpan data musiknya tidak berupa Disket seperti pada umumnya, melainkan berupa antara lain: SD card, flash disk, dan sebagainya.

Adapun cara untuk menyimpan data musik yang baru saja dikerjakan di depan adalah dengan cara sebagai berikut :

1) Tekan tombol "DISK" (tombol warna kuning).

2) Tunggu sebentar hingga pada layar tampak tulisan "DISK MENU".

3) Tekan "SAVE" (pada layar kibot).

4) Tekan Tenchnics Format (pada layar kibot).

5) Tekan "NAME"

6) Tulis Nama style yang kita buat.

7) Tekan "OK" (pada layar kibot).

8) Tekan "SAVE" (pada layar kibot).

Tunggu sampai muncul tulisan “COMPLETED”. 
Dengan dua pemrograman yang telah kita lakukan di depan (pemrograman peniruan bunyi Kendang dan membuat style), selanjutnya kita bisa memainkan lagu yang sudah kita rancang untuk dimainkannya. Oleh karena pemrograman tersebut di depan dengan style, maka untuk memainkannya seorang pemain keyboard musti dapat memainkan akord-akord pada keyboard.

\section{G. Penutup}

Kecemasan suatu bangsa terhadap terdesaknya eksistensi diri dalam berbagai hal merupakan suatu kewajaran. Bangsa kita Indonesia yang memiliki kekayaan budaya yang beraneka ragam oleh karena terdiri dari macam-macam suku bangsa, memang layak merasakan terdesak oleh derasnya budaya bangsa lainnya termasuk bangsa barat melalui arus globalisasi.

Perasaan terdesaknya bangsa kita Indonesia ini misalnya tentang kekayaan kesenian daerahnya, seperti seni musik yang terdapat di Pulau Jawa dengan gamelannya, kini benar-benar terdesak oleh hingar-bingarnya musik barat yang dari waktu ke waktu semakin dianggap menarik. Terdesaknya terutama dalam hal rasa memilikinya yang semakin terasa rendah. Terbukti antara lain generasi mudanya yang lebih banyak menikmati, juga memainkan musik-musik dari luar negeri. Mendengarkan/menikmati, juga memainkan musik gamelan dianggapnya kuno.

Untuk itu melalui media canggih keyboard, merupakan salah satu langkah konkrit untuk paling tidak memperdengarkan musik gamelan. Dengan diperdengarkannya secara terus-menerus musik gamelan melalui keyboard dalam berbagai event, diharapkan dapat paling tidak menikmati musik milik bangsa kita sendiri: gamelan.

\section{Daftar Pustaka}

Blades, James. 1984. Percussion Instruments and their History. London: Faber and Faber.

Midgley, Ruth. 1989. Musical Instruments of The World. Brussel: Musee Instrumental.

Djohan. 2005. Psikologi Musik. (Cetakan kedua). Yogyakarta: Penerbit Buku Baik.

Yudoyono, Bambang. 1984. Gamelan Jawa. Jakarta: PT Karya Unipress.

Ulrich, Homer. 1970. Music: A Design for Listening. Third Edition. New York: Harcourt, Brace, \& World. Inc.

Im aji. Vol.3. No.2. Agustus 2005: $257-272$ 
Kawakami, Genichi. 1975. Arranging Popular Music: A Practical Guide. Tokyo: Yamaha Music Foundation.

Miller, M. Hugh. 1998. Pengantar Apresiasi Musik (Terjemahan Triyono, Bramantyo). Yogyakarta.

Paap, Wouter. 1953. Manusia dan Musik. Jakarta: Balai Pustaka.

Banoe, Pono. 1984. Pengantar Pengetahuan Alat Musik. Jakarta: CV Baru.

Ocvirk, Otto G., dkk. 1962. Art Fundametals. Iowa: W.M. C. Brown

Rasmusen, Henry N. 1950. Art Structure. New York: McGraw-Hill Book.

Read, Herbert. 1968. Art Now. London: Faber and Faber. 